\title{
Research
}

\section{Effect of ethnicity on the prevalence, severity, and management of COPD in general practice}

\begin{abstract}
\section{Background}

Chronic obstructive pulmonary disease (COPD) remains a major cause of mortality and hospital use. Little is known in the UK about the variation in COPD prevalence, severity, and management depending on ethnicity.
\end{abstract}

\section{Aim}

To examine differences by ethnicity in COPD prevalence, severity, and management.

\section{Design \& setting}

Cross-sectional study using routinely collected computerised data from general practice in three east-London primary care trusts (Newham, Tower Hamlets, and City and Hackneyl with multiethnic populations of people who are socially deprived.

\section{Method}

Routine demographic, clinical, and hospital admission data from 140 practices were collected.

\section{Results}

Crude COPD prevalence was 0.9\%; the highest recorded rates were in the white population. Severity of COPD, measured by percentagepredicted forced expiratory volume in 1 second did not vary by ethnicity. South Asians and black patients were less likely than white patients to have breathlessness, indicated by a Medica Research Council dyspnoea grade of $\geq 4$ lodds ratio [OR] 0.7 [95\% confidence interval $(\mathrm{Cl})=0.6$ to $0.9]$ and 0.6 [95\% $\mathrm{Cl}=0.4$ to 0.8$]$ ]. Black patients were less likely than white patients to receive inhaled medications. Influenza and pneumococcal vaccine rates were highest among groups of South Asians (OR $3.0[95 \% \mathrm{Cl}=2.1$ to 4.3] and $1.8[95 \% \mathrm{Cl}=1.4$ to 2.3$]$ respectively] Both minority ethnic groups had low referral rates to pulmonary rehabilitation. In Tower Hamlets, black patients were more likely to be admitted to hospital for respiratory causes.

\section{Conclusion}

Differences in COPD prevalence and severity by ethnicity were identified, and significant differences in drug and non-drug management and hospital admissions observed. Systematic ethnicity recording in general practice is needed to be able to explore such differences and monitor inequalities in healthcare by ethnicity.

\section{Keywords}

chronic disease management; chronic

obstructive pulmonary disease; ethnicity; genera practice; health inequalities.
INTRODUCTION

In the UK, chronic obstructive pulmonary disease (COPD) accounts for 30000 deaths a year, $1.4 \%$ of GP consultations, $2 \%$ of hospital admissions, and costs the NHS $£ 800$ million. ${ }^{1}$ The main cause of COPD is tobacco smoking. ${ }^{2}$ but it is also associated with other factors such as occupational exposure, ${ }^{3}$ urban living, ${ }^{4}$ alpha-1 antitrypsin deficiency, ${ }^{5}$ and childhood respiratory infections. ${ }^{6,7}$ The majority of routine COPD management takes place in primary care, with the most effective intervention being smoking cessation. The COPD guidelines from the National Institute for Health and Clinical Excellence (NICE) recommend a stepwise approach to COPD prescribing and a range of non-pharmacological interventions. $^{8}$

The Quality and Outcomes Framework (QOF) data from general practice estimates the UK COPD prevalence to be $1.4 \%$, but epidemiological studies suggest the prevalence is considerably higher - a crosssectional study using data from the Health Survey for England estimated the UK COPD prevalence to be $3.1 \%$ in $2005 .{ }^{1}$ COPD is more prevalent in males, older people, and populations that are deprived and urban. There is little data on the variation in UK COPD prevalence by ethnicity; Nacul et al found high COPD prevalence in black males and low COPD prevalence in South Asian females in the UK, but did not adjust for deprivation. ${ }^{1}$ In the US, Chatila et al found that African Americans presented with COPD at a younger age than white populations,

A Martin, BSc, medical student, Barts and the London School of Medicine and Dentistry, London. E Badrick, BSc, research fellow: R Mathur, MSc, research fellow; S Hull, MSc, MRCP, FRCGP, reader in primary care development, Centre for Primary Care and Public Health, Queen Mary University of London, London.

\section{Address for correspondence}

Rohini Mathur, Yvonne Carter Building, 58 Turner Street, London, E1 2AB. despite smoking less. ${ }^{9}$ However, in a different US study, Vollmer et al found no significant difference in COPD prevalence by ethnicity. ${ }^{10}$ COPD prevalence is known to be strongly associated with smoking prevalence. The 2004 Health Survey for England found that males from minority ethnic groups were more likely, and females less likely, to smoke than the general population. ${ }^{11}$

This study was set in three contiguous inner east London primary care trusts (PCTs) where $53 \%$ of the population are members of minority ethnic groups; this is a much higher proportion than in the whole UK population, in whom minority ethnic groups total $7.9 \% .^{12}$ The populations of these three east London PCTs are among the eight most deprived localities in Britain. ${ }^{13}$ The aim of this study was to examine the effect of ethnicity on the prevalence, severity, and management of COPD.

\section{METHOD}

A total of 140 general practices in eas London contributed routinely collected data as part of a regular annual audit of chronic disease management. ${ }^{14}$ These practice data cover $98 \%$ of the GP-registered population in the three PCTs 1920000 in February 2011).

\section{Clinical data collection}

Practice computer databases were interrogated using Egton Medical Information Systems web software. As Read Codes are the clinical classification system

E-mail: r.mathurdamul.ac.uk

Submitted: 23 August 2011; Editor's response: 20 September 2011; final acceptance: 31 October 2011

@British Journal of General Practice

This is the full-length article (published online 30 Jan 2012) of an abridged version published in print. Cite this article as: Br J Gen Pract 2012; DOI: 10.3399/bjgp12X625120 


\section{How this fits in}

In the UK, chronic obstructive pulmonary disease (COPD) accounts for 30000 deaths a year, however there is little data on the variation in UK COPD prevalence by ethnicity. This study used practice data from east London to show the variation in COPD prevalence, severity and management by ethnicity.

used in UK general practice, all adult patients aged $\geq 35$ years with a computerised diagnostic Read Code for COPD were included. ${ }^{15}$ Data was anonymised and managed according to NHS information governance requirements. ${ }^{16}$ Variables included in the analysis were recorded between 1 January 2009 and 31 December 2010.

Clinical data included percentagepredicted forced expiratory volume in 1 second (FEV1\%) - a low FEV1\% denotes poor lung function and more severe COPD. The latest NICE guidance groups FEV1\% into the following categories: very severe $(<30)$; severe (30-49); moderate (50-79); and mild $(\geq 80)$. The Medical Research Council (MRC) dyspnea scale indicates the level of symptoms related to breathlessness reported by the patient; higher scores indicate worse symptoms of breathlessness.

Other clinical variables included: smoking status lgrouped into current smoker and non-current smoker, including ex-smokers); blood pressure; total cholesterol; body mass index (BMI); and diagnosis of ischaemic heart disease, hypertension, diabetes, and asthma.

Process of care variables included pneumococcal immunisation, influenza immunisation, referral to pulmonary rehabilitation, and an annual COPD review. Prescription data included short-acting betaagonists (SABAs), short-acting muscarinicantagonists (SAMAs), long-acting betaagonists (LABAs), long-acting muscarinicantagonists (LAMAs), inhaled corticosteroids (ICs), combined inhaled corticosteroids/longacting beta-agonists (ICs/LABAs), and theophylline. Hospital admissions (Tower Hamlets PCT population only) were collected using healthcare resource group categories. For each patient, a measure of all hospital inpatient episodes and respiratory specific episodes was included.

\section{Ethnicity and socioeconomic variables}

Self-reported ethnicity was recorded at the practice during registration or routine consultations. Ethnic groups were based on the UK 2001 Census and, for this study, were collapsed into five categories:

- white (British, Irish, other white);

- black (black African, black Caribbean, black British, other black, and mixed black);

- South Asian (Bangladeshi, Pakistani, Indian, Sri Lankan, British Asian, other South Asian, or mixed Asian);

- Other (Chinese, other ethnic groups, other mixed groups); and

\section{- Unknown.}

Missing or incomplete data were recorded as 'unknown' Isee online UK 2001 Census ethnic groups for full details ${ }^{12}$ ). The Townsend score, based on the postcode of residence of each individual, was used as a marker of social deprivation.

Using the ethnicity data recorded in the total general practice population, the agebanded prevalence of COPD in 10-year age bands for the three major ethnic groups in the population (white, black, and South Asian) were calculated. Overall ethnicity recording in the general east London population is $80 \% .{ }^{17}$ Previous research has shown that, at these levels of recording, using the practice data as denominator gives robust prevalence estimates, equivalent to using ethnic population projections from other sources, such as the Greater London Authority. ${ }^{17}$

\section{Statistical analysis}

All statistical analyses used Stata (version 9, StataCorp). In descriptive statistics, categorical variables were assessed for differences by using a $\chi^{2}$ test; continuous numerical variables were assessed using analysis of variance.

Differences in the prevalence and severity of COPD between ethnic groups were expressed as odds ratios (ORs) using stepwise logistic regression, with white ethnicity considered as neutral risk (OR 1.0). Analyses were adjusted by patient characteristics lage, sex, Townsend score, PCT, and asthma diagnosis, and clustered by general practice). The MRC dyspnoea scale was also adjusted by the comorbidity of hypertension, ischemic heart disease, and diabetes. Drug prescribing, nonpharmacological managements, and hospital admission rates were also adjusted by the FEV1\% severity indicator.

\section{RESULTS}

Of the 7901 cases of GP-recorded COPD, ethnicity was recorded for $98.7 \%$ and 


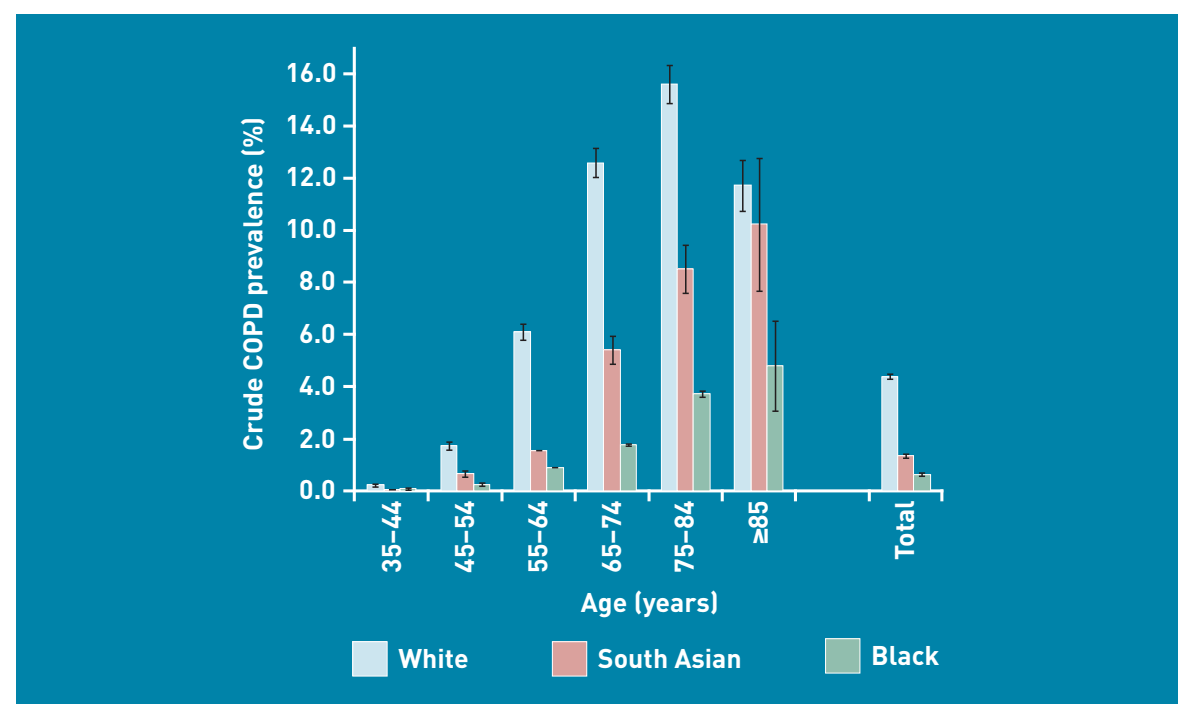

Figure 1. GP recorded prevalence of COPD by age and ethnicity, using practice list size as denominator (95\% Cls).

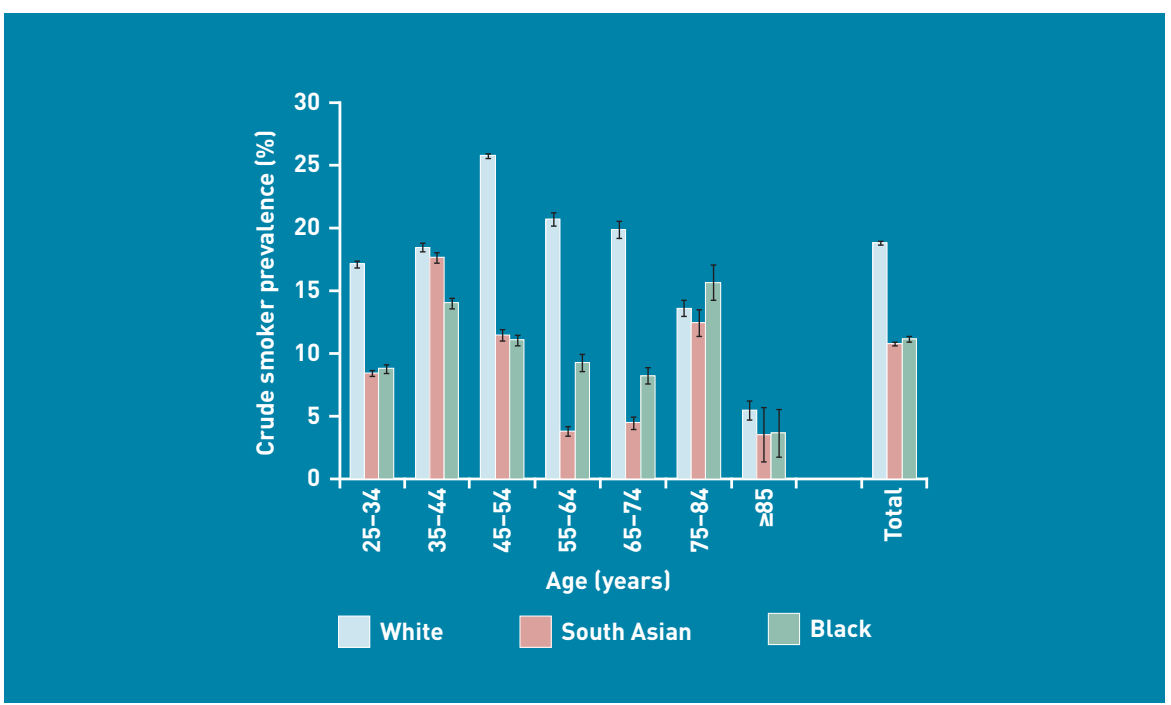

Figure 2. Prevalence of GP recorded smoking by age and ethnicity, using practice list size as a denominator (95\% Cls). spirometry values in the previous 2 years were available for 5471. There was no significant difference in missing spirometry values between the three ethnic groups.

Crude COPD prevalence in the eastLondon population is $0.9 \%$. (1.5\% when adjusted to the European standard population. ${ }^{18}$ The recorded COPD prevalence for those aged $\geq 35$ years in the study population was $2.5 \%$. The highest prevalence was in the white population (4.4\%); prevalence in the South Asian group was $1.3 \%$, and the lowest rates were recorded in

\section{Table 1. COPD and current smoker status, by ethnicity}

\begin{tabular}{lccc} 
Ethnic group & $\boldsymbol{n}$ & $\begin{array}{c}\text { \% with COPD } \\
\text { still smoking }\end{array}$ & $\begin{array}{c}\text { ORs (95\% CI)a for } \\
\text { those continuing to smoke }\end{array}$ \\
\hline White (reference group) & 5987 & 42.0 & 1.0 \\
\hline South Asian & 1086 & 27.3 & $0.5(0.4$ to 0.6$)$ \\
\hline Black & 418 & 33.1 & $0.6(0.5$ to 0.8$)$ \\
\hline
\end{tabular}

${ }^{a}$ Adjusted by sex, age, Townsend score, primary care trust, clustered by general practice. COPD = chronic obstructive pulmonary disease. $O R=$ odds ratio. the black population (0.6\%) (Figure 1). Figure 1 also shows that the white population had the highest prevalence of COPD in all age groups.

The prevalence of COPD by sex varied greatly by ethnicity. In the white population, $48.2 \%$ were male; in contrast, $81.2 \%$ and $64.4 \%$ were male in the South Asian and black populations respectively.

The major risk factor for COPD is smoking. The prevalence of GP-recorded current smoking rates in the adult population for the main ethnic groups in this study is shown in Figure 2. Smoking prevalence was 13.1\% among those aged >25 years. The white population had the highest smoking prevalence at 18.8\%; the prevalence among South Asians was $10.8 \%$ and $11.2 \%$ in the black population

Smoking patterns by sex varied between ethnic groups and reflected the sex distribution of COPD prevalence. Among white smokers, $64.2 \%$ were male, among the South Asian group $88.7 \%$ were male, and in the black population $73.0 \%$ were male (data not shown).

Smoking prevalence by ethnicity was then examined within the COPD population. Table 1 illustrates that South Asian and black patients with COPD are much less likely to be current smokers than white patients. This suggests that these groups are more likely to stop smoking when there is a diagnosis of COPD.

The severity of COPD by ethnicity was examined using both FEV1\% values and MRC breathlessness scores (Table 2). Using logistic regression, no difference was found in FEV1\% by ethnicity when adjusting for demographic variables, Townsend score PCT, and asthma, and clustering by practice. However, compared with the white population, both South Asian and black populations were less likely to have an MRC grade of $\geq 4$, OR 0.6 (95\% confidence interval $[\mathrm{Cl}]=0.4$ to 0.8$)$ and $0.7(95 \% \mathrm{Cl}=0.6$ to 0.9$)$ respectively; this suggests less severe symptomatic breathlessness in these groups, compared with white patients.

\section{Drug prescribing and}

\section{non-pharmacological management}

Table 3 shows, by ethnicity, the prevalence of prescribing for each major COPD drug treatment type and key non-pharmacological management interventions. At the time of the study, only $56.3 \%$ of the whole COPD population was on a SABA; in contrast, more than three-quarters of the cohort was on either ICs alone $(27.3 \%$ ) or ICs combined with a LABA (51.9\%). Less than a fifth of patients with COPD had a record of referral to 
Table 2. FEV1\% and MRC breathlessness scores, by ethnicity

\begin{tabular}{lcccc} 
& White (\%) & South Asian (\%) & Black (\%) & Total (\%) \\
\hline FEV1\% & & & & \\
$\geq 80$ & $807(18.5)$ & $162(19.9)$ & $42(14.2)$ & $1011(18.5)$ \\
$50-79$ & $2232(51.2)$ & $397(48.7)$ & $154(52.2)$ & $2783(50.9)$ \\
$30-49$ & $1052(24.1)$ & $207(25.4)$ & $77(26.1)$ & $1336(24.4)$ \\
$<30$ & $270(6.2)$ & $49(6.0)$ & $22(7.5)$ & $341(6.2)$ \\
Total & $4361(100.0)$ & $815(100.0)$ & $295(100.0)$ & $5912(100.0)$ \\
\hline MRC & & $753(79.8)$ & $301(84.6)$ & $5052(76.2)$ \\
Grade 1, 2, or 3 & $3998(75.0)$ & $191(20.2)$ & $55(15.4)$ & $1576(23.8)$ \\
Grade 4 or 5 & $1330(25.0)$ & $944(100.0)$ & $356(100.0)$ & $6628(100.0)$ \\
Total & $5328(100.0)$ & &
\end{tabular}

\section{Table 3. Prevalence of drugs prescribed and non-pharmacological management, by ethnicity}

\begin{tabular}{|c|c|c|c|c|}
\hline & White (\%) & South Asian (\%) & Black (\%) & Total (\%) \\
\hline \multicolumn{5}{|l|}{ Drug prescribed } \\
\hline SABA & 57.3 & 47.7 & 64.4 & 56.3 \\
\hline SAMA & 15.2 & 12.2 & 9.7 & 14.4 \\
\hline LABA & 11.3 & 8.0 & 8.1 & 10.7 \\
\hline LAMA & 47.2 & 42.8 & 38.2 & 46.1 \\
\hline Combined ICs/LABA & 51.4 & 56.0 & 47.5 & 51.9 \\
\hline ICs & 27.0 & 28.5 & 28.5 & 27.3 \\
\hline Theophylline & 10.0 & 10.4 & 5.9 & 9.8 \\
\hline \multicolumn{5}{|l|}{ Non-pharmacological management } \\
\hline Influenza vaccination & 84.7 & 94.1 & 83.1 & 86.0 \\
\hline Pneumococcal vaccination & 73.6 & 82.6 & 70.6 & 74.8 \\
\hline Referral to pulmonary rehabilitation & 19.3 & 16.7 & 12.6 & 18.5 \\
\hline
\end{tabular}

$I C=$ inhaled corticosteroid. $L A B A=$ long-acting beta-agonist. $L A M A=$ long-acting muscarinic-agonist. $S A B A=$ short-acting beta-agonist. SAMA = short-acting muscarinic-agonist

\section{Table 4. The management of COPD, by ethnicity}

\begin{tabular}{lccc} 
& \multicolumn{3}{c}{ Ethnicity } \\
\cline { 2 - 4 } Intervention & White $(\boldsymbol{n}=\mathbf{4 3 5 1 )}$ & South Asian $(\boldsymbol{n}=\mathbf{8 1 3})$ & Black $(\boldsymbol{n}=295)$ \\
\hline Drug prescribed, OR $(95 \% \mathrm{Cl})^{\mathrm{a}}$ & & & \\
SABA & $1.0^{\mathrm{b}}$ & $1.0(0.7$ to 1.3$)$ & $0.7(0.5$ to 0.9$)$ \\
SAMA & $1.0^{\mathrm{b}}$ & $0.9(0.7$ to 1.2$)$ & $0.6(0.4$ to 0.9$)$ \\
LABA & $1.0^{\mathrm{b}}$ & $0.8(0.6$ to 1.1$)$ & $0.7(0.5$ to 1.0$)$ \\
LAMA & 1.0 & $0.8(0.6$ to 0.9$)$ & $0.7(0.5$ to 0.9$)$ \\
ICS & 1.0 & $1.1(0.9$ to 1.3$)$ & $1.2(0.9$ to 1.5$)$ \\
ICs/LABA & 1.0 & $1.1(0.9$ to 1.3$)$ & $0.8(0.6$ to 1.0$)$ \\
Theophylline & 1.0 & $0.9(0.7$ to 1.3$)$ & $0.4(0.2$ to 0.7$)$ \\
\hline Non-pharmacological intervention, OR $(95 \% \mathrm{CI})^{\mathrm{a}}$ & & \\
Influenza vaccination & $1.0^{\mathrm{b}}$ & $3.0(2.1$ to 4.3$)$ & $0.8(0.5$ to 1.1$)$ \\
Pneumococcal vaccination & $1.0^{\mathrm{b}}$ & $1.8(1.4$ to 2.3$)$ & $0.82(0.6$ to 1.1$)$ \\
Pulmonary rehabilitation & $1.0^{\mathrm{b}}$ & $0.7(0.6$ to 0.9$)$ & $0.7(0.5$ to 1.0$)$
\end{tabular}

${ }^{a}$ Adjusted by age, sex, Townsend score, PCT, FEV $1 \%$, and asthma, and clustered by general practice. ${ }^{b}$ Reference group. $I C=$ inhaled corticosteroid. $L A B A=$ long-acting beta-agonist. $L A M A=$ long-acting muscarinic-agonist. $O R=$ odds ratio. $S A B A=$ short-acting beta-agonist. SAMA = short-acting muscarinic-agonist .

pulmonary rehabilitation (18.5\%)

The adjusted analysis in Table 4 shows that black patients are less likely to receive SABAs, SAMAs, LAMAs, combined ICs/LABAs, and theophylline, compared with their white counterparts. South Asians are less likely to receive LAMAs ladjusted OR 0.8 $[95 \% \mathrm{Cl}=0.6$ to 0.9$]$ ] than their white counterparts. No difference was found for LABAs and ICs prescribed separately, by ethnicity.

Table 4 shows that among the nonpharmacological interventions, South Asians are more likely to receive both influenza and pneumococcal immunisations compared with white or black populations. Both South Asian and black patients are less likely to receive pulmonary rehabilitation referral compared with white patients.

\section{Hospital admissions}

Due to technical limitations, hospital admissions data were only available for the Tower Hamlets PCT population. This analysis ladjusted by COPD severity and asthma comorbidityl showed that patients who were black and had COPD were more likely to have an episode as a hospital inpatient, be it for any cause lOR $1.5[95 \% \mathrm{Cl}=1.0$ to 2.1$]$ or for respiratory-specific causes (OR $2.3[95 \% \mathrm{Cl}=$ 1.1 to 4.6$]$ ).

\section{DISCUSSION}

\section{Summary}

The results of this study demonstrate clear differences in COPD prevalence, smoking status, severity, management, and hospital admissions by ethnicity. COPD among the white population was recorded in younger groups and had a greater prevalence at all ages in comparison with other ethnic groups in east London. COPD in the white population was equally distributed by sex, while for black and South Asian groups both smoking rates and COPD were more common among males. Among those with COPD, smoking rates remained much higher in the white population, in comparison with other groups.

Both South Asian and black populations reported less severe breathlessness symptoms than their white counterparts; this could suggest that they have a milder COPD or that symptoms are better tolerated or managed in comparison with the white population. These findings showed that, for COPD drug prescribing, there was a trend for the black population to be on less medication in comparison to the white population, regardless of symptoms or severity; in contrast, South Asians were largely on a similar range of medications - apart from lower rates of LAMA. South Asian patients were also more likely to have influenza and pneumococcal vaccinations than other groups.

Among the Tower Hamlets population, black patients were more likely to be admitted to hospital for any cause, and for COPD-related admissions than white or South Asian groups. This may suggest these 
groups have more frequent and severe exacerbations, and may be linked to the observed lower rates of prescribed medications.

\section{Strengths and limitations}

The high levels of self-reported ethnicity in this study population enable robust estimation of the prevalence of COPD by ethnicity. However, the low overall prevalence suggests that case identification in general practice is suboptimal. Improving the rate of detection of COPD towards the estimated prevalence of $3 \%$ identified by the British Lung Foundation is now an important task in primary care. $^{19}$

Study limitations include a reliance on routine clinical data entry during consultations, which may have introduced data of varying quality. Spirometry values recorded in the previous 2 years were available for $61 \%$ of cases, so there is the possibility of diagnostic inaccuracy within the cohort. A lack of routinely recorded data on pack years means there is a dearth of detail on the variation in smoking intensity between groups. In addition, differences could exist in the perception or reporting behaviour by ethnicity that might explain the differences in symptoms that were noted.

\section{Comparison with existing literature}

Variation in prevalence by ethnicity has been observed both in the UK' ${ }^{1}$ and the US9,10 but, as far as the authors are aware, this is the first attempt to examine COPD management by ethnicity in UK primary care.

Simpson et al found higher rates of smoking continuation associated with social deprivation in England, but did not include analysis by ethnicity. ${ }^{20}$ It is possible that these differences may reflect variation in smoking habits between ethnic groups; information on pack years was not available, which may be an important variable in influencing smoking cessation.

Although there is a lack of research into differences in COPD management according to ethnicity, there is evidence from studies on other chronic diseases, particularly cardiovascular disease, which demonstrate similar patterns in the use of prescribed medicines; that is, higher rates among South Asians and lower rates among black populations. ${ }^{21-24}$ The reasons for these differences are uncertain. Given the equitable access to care in the UK NHS, differential registration and access to primary and secondary care services are unlikely to play a role; differential take-up of medicines due to cost is also unlikely in this population as the majority are of retirement age and, hence, eligible for free prescriptions. It is possible that differences in health beliefs and the understanding of COPD between groups may influence medication use and approaches to selfmanagement. Studies in asthma have identified lower levels of confidence in selfmanaging acute attacks among South Asians, which contributes to higher rates of hospital admission than white groups. ${ }^{25}$

\section{Implications for practice}

Improving the primary care management of patients with COPD is important both for optimal symptom management and to reduce the rate of exacerbation and the need for hospital admission. Drug management in this cohort was suboptimal, with surprisingly low rates of SABA prescribing. In contrast, there were high rates of IC prescribing, either alone or in combination with a LABA, in spite of the fact that only $30.6 \%$ of cases had an FEV $1 \%$ of $<50$. The most recent NICE guidance ${ }^{8}$ supports the use of combined LABAs and ICs in moderate but symptomatic or exacerbating COPD, but this does come with the risk of increased rates of pneumonia.

Recorded asthma comorbidity was high in this cohort and particularly so among the South Asian population (data available from the author on request). It is unclear whether this was due to diagnostic uncertainty or genuine differences in comorbidity. Referral rates to pulmonary rehabilitation at $18.5 \%$ remain low, particularly among minority ethnic groups, although these rates are an improvement on the national $5 \%$ referral rates quoted in $2006 .{ }^{26}$

Equitable access and utilisation of healthcare remains a priority for the Department of Health, and the recent Marmot review emphasises the importance of identifying and monitoring inequalities as a first stage to intervention. ${ }^{27}$ Routine audit data, such as the QOF in the UK, does not include ethnicity as a measure, which restricts its use as a tool for commissioning in multiethnic areas and as a framework for monitoring inequalities by ethnicity in the management of chronic disease. The findings of this study will be relevant to other areas in the UK that have large minority ethnic populations, but differences in the management of COPD by ethnicity need to be explored further, and addressed, in order to reduce outcomes inequalities. Further work is needed to understand the differences in prescribing rates by ethnicity, and how this relates to the severity of symptoms and perceptions of the disease in different groups. 


\section{REFERENCES}

1. Nacul L, Soljak M, Meade T. Model for estimating the population prevalence of chronic obstructive pulmonary disease: cross sectional data from the Health Survey for England. Popul Health Metr 2007; 5: 8.

2. Frew AJ, Holgate ST. Respiratory disease. In: Kumar PJ \& Clark ML (eds.). Kumar \& Clark's clinical medicine. 6th edn. Edinburgh: Saunders Elsevier, 2005: 900-906.

3. Bakke P, Baste V, Hanoa R, Gulsvik A. Prevalence of obstructive lung disease in a general population: relation to occupational title and exposure to some airborne agents. Thorax 1991; 46(12): 863-870.

4. Pride N, Soriano J. Chronic obstructive pulmonary disease in the United Kingdom: trends in mortality, morbidity, and smoking. Curr Opin Pulm Med 2002; 8(2): 95-101.

5. Devereux G. ABC of chronic obstructive pulmonary disease. Definition epidemiology, and risk factors. BMJ 2006; 332(7550): 1142-1144.

6. Galobardes B, McCarron P, Jeffreys M, Davey Smith G. Association between early life history of respiratory disease and morbidity and mortality in adulthood. Thorax 2008; 63(5): 423-429.

7. Barker D, Godfrey K, Fall C, et al. Relation of birth weight and childhood respiratory infection to adult lung function and death from chronic obstructive airways disease. BMJ 1991; 303(6804): 671-675.

8. National Institute for Clinical Excellence. Management of chronic obstructive pulmonary disease in adults in primary and secondary care (partial update). This guideline partially updates and replaces NICE clinical guideline 12. London: NICE, 2004. http://guidance.nice.org.uk/CG101 laccessed 22 Dec 2011).

9. Chatila W, Wynkoop W, Vance G, Criner G. Smoking patterns in African Americans and whites with advanced COPD. Chest 2004; 125(1): 15-21.

10. Vollmer W, Enright P, Pedula K, et al. Race and gender differences in the effects of smoking on lung function. Chest 2000; 117(3): 764-772

11. Health Survey for England. The health of minority ethnic groups, Summary of key findings. Leeds: The Health and Social Care Information Centre, 2006. http://www.ic.nhs.uk/webfiles/publications/healthsurvey2004ethnicfull/Health SurveyforEngland210406_PDF.pdf (accessed 22 Dec 2011).

12. Office of National Statistics. Presenting ethnic and national groups data. London: Crown Copyright, 2008

13. Communities and Local Government. Indices of deprivation 2007. London: Crown copyright, 2007

http://www.communities.gov.uk/publications/communities/indiciesdeprivation 07 laccessed 22 Dec 2011).
14. Blizard Institute. Clinical effectiveness group (CEG). London: Queen Mary's University, 2010. http://www.icms.qmul.ac.uk/chs/ceg/index.html laccessed 22 Dec 2011).

15. Chisholm J. The Read clinical classification. BMJ 1990; 300(6732): 1092.

16. NHS Connecting for Health. Principles of information security. London: Crown copyright, 2010

http://www.connectingforhealth.nhs.uk/systemsandservices/infogov/security laccessed 22 Dec 2011).

17. Hull S, Mathur R, Badrick E, et al. Recording ethnicity in primary care: assessing the methods and impact. Br J Gen Pract 2011; 61(586): e290-294.

18. Department of Health. Clinical indicators. ANNEX D1: Age-standardisation and calculating confidence intervals. London: DoH, 2000.

19. British Lung Foundation. Invisible lives: chronic obstructive pulmonary disease (COPD) - finding the missing millions. London: British Lung Foundation.

http://www.lunguk.org/Resources/British\%20Lung\%20Foundation/Migrated\% 20Resources/Documents///Invisible\%20Lives\%20report.pdf laccessed 22 Dec 2011).

20. Simpson CR, Hippsley-Cox J, Sheikh A. Trends in the epidemiology of chronic obstructive pulmonary disease in England: a national study of 51804 patients. Br J Gen Pract 2010; 60(576): 483-488.

21. Ashworth M, Lloyd D, Smith R, et al. Social deprivation and statin prescribing: a cross-sectional analysis using data from the new UK general practitioner 'Quality and Outcomes Framework'. J Public Health (Oxf) 2007; 29(1): 40-47.

22. Britton A, Shipley M, Marmot M, Hemingway H. Does access to cardiac investigation and treatment contribute to social and ethnic differences in coronary heart disease? Whitehall II prospective cohort study. BMJ 2004; 329(7461): 318

23. Gill P, Quirke T, Mant J, Allan T. The use of lipid-lowering drugs across ethnic groups in the secondary prevention of ischaemic heart disease: analysis of cross-sectional surveys in England. Br J Gen Pract 2004; 54(503): 442-443.

24. Mathur R, Badrick E, Boomla K, et al. Prescribing in general practice for people with coronary heart disease; equity by age, sex, ethnic group and deprivation. Ethn Health 2011; 16(2): 107-123.

25. Griffiths C, Kaur G, Gantley M, et al. Influences on hospital admission for asthma in south Asian and white adults: qualitative interview study. BMJ 2001; 323(7319): 962-966

26. White P. COPD in primary care: a time of opportunity (editorial). $\mathrm{Br} J \mathrm{Gen}$ Pract 2010; 60(576): 477-478.

27. Global Health Equity Group. Strategic review of health inequalities in England post-2010. (The Marmot Review). London: UCL and The Marmot Review, 2010. http://www.ucl.ac.uk/gheg/marmotreview laccessed 22 Dec 2011). 